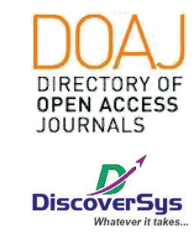

Published by DiscoverSys

\section{Iron-deficiency anemia: A review of diagnosis and management}

\author{
Putu Amanda Widiada*
}

CrossMark

\title{
ABSTRACT
}

Background: Anemia is the most common medical problem encountered in daily practice. It is a significant health problem, especially in developing countries that have a high prevalence. Irondeficiency anemia (IDA) is anemia that arises due to decrease in iron supply for erythropoiesis regarded with lack of iron storage that consequently leads to reduced haemoglobin formation.

Aim: This literature review aims to review diagnosis to the management of IDA.
Conclusion: IDA has severe and detrimental health effects. Complete history taking, physical examination, and laboratory test need to be done thoroughly to be able to establish the diagnosis of IDA as well as to determine its cause. Currently used therapies include oral iron therapy which is the first-line therapy, intravenous iron therapy, and blood transfusion.
Mangusada General Hospital, Badung Regency, Bali

*Correspondece to: Putu Amanda Widiada, Mangusada General Hospital, Badung Regency, Bali

amandawidiada@yahoo.co.id

Received: 2019-08-01 Accepted: 2020-09-09 Published: 2020-03-03

Keywords: haemoglobin, erythrocytes, iron fortification, anemia

Cite this Article: Widiada, P.A. 2020. Iron-deficiency anemia: A review of diagnosis and management. Intisari Sains Medis 11(1): 92-96. D0I: 10.15562/ism.v11i1.578

\section{INTRODUCTION}

Anemia is the most common medical problem encountered in daily practice. Anemia by functional defined as a decrease in the number of erythrocyte masses so thus it cannot fulfil its function to carry an adequate amount of oxygen to peripheral tissue. ${ }^{1}$ Anemia is not a disease, but a part of the symptoms of an underlying illness, whether it was acquired or inherited. ${ }^{2}$

Anemia is a significant health problem especially in developing countries that have a high prevalence. Based on analysis from World Health Organization (WHO) in 2008 , anemia affects $24.8 \%$ population all over the world, including $42 \%$ pregnant women, $30 \%$ non-pregnant women, and $47 \%$ pre-school children. In the study conducted by Kassebaum et al., it was estimated that the anemia prevalence globally in 2010 was $32.9 \%$ resulting in 68.4 million year life in disability. There are three leading causes of anemia including iron deficiency anemia, hemoglobinopathy, and malaria. ${ }^{3}$

IDA is anemia that arises due to a decrease in iron supply for erythropoiesis, because of empty iron storage that consequently leads to reduced haemoglobin formation. ${ }^{1}$ IDA is the most commonly found anemia and contributes 50\% of all anemia sources. In developing country, this anemia was detected $2-4 \%$ in women aged $20-49$ years old, and $11 \%$ in men over 50 years old. ${ }^{4}$ IDA can disturb adult's ability to work and interfere with children growth and development. This anemia has severe and detrimental health effects.

\section{IRON-DEFICIENCY ANEMIA}

Iron deficiency is defined as a decrease in the total amount of iron in the body. Iron deficiency anemia occurs when iron deficiency is severe enough to interfere with the erythropoiesis process resulting in anemia symptoms to arise. This happens when the balance between iron intake, iron storage, and iron loss from the body cannot meet erythrocyte production. ${ }^{5}$

\section{Iron Metabolism}

Erythropoiesis requires iron in its process, which is regulated by three variables that are tissue oxygenation, erythrocyte replacement, and loss of erythrocyte through bleeding. Around $20 \mathrm{ml}$ of old erythrocytes are destroyed, and $20 \mathrm{mg}$ of iron in those erythrocytes are recycled for production of new erythrocytes. Erythrocytes and its precursors require iron in large amounts to produce heme and hemoglobin. ${ }^{6}$

Iron is the core that is very important for the structure and functions of haemoglobin. Iron deficiency anemia is associated with low iron saturation that binds to transferrin. The iron that is linked to transferrin originated from the intestines, macrophages, and liver. Nutritional intake and iron from the recycling process of erythrocytes must be able to meet the needs for erythrocyte production. If this is not balanced and iron loss occur continuously, then the newly formed erythrocytes will have a reduced amount of haemoglobin so that they cannot carry out their functions for oxygenation properly. ${ }^{7}$ 
The process of iron metabolism is used for the formation of haemoglobin, where iron will be processed continuously. Iron contained in food in the form of $\mathrm{Fe} 3+$ (ferric iron) and $\mathrm{Fe} 2+$ (ferrous iron) will be digested in the stomach. During the digestion process in the stomach $\mathrm{Fe} 3+$ will be reduced to $\mathrm{Fe} 2+$ to be absorbed by the intestine which is mediated by Ferri reductase and facilitated by ascorbic acid. In the gut, $\mathrm{Fe} 2+$ is transported into enterocytes through divalent metal transporter 1 (DMT-1). Fe2+ has oxidized again to Fe3+ which then binds to apoferritin and transforms and is stored in the form of ferritin. Fe2+ can also be carried to the basolateral membrane to be transported to the blood plasma by feroprotein. ${ }^{6}$ Some amount of $\mathrm{Fe} 2+$ is released into the blood plasm, where $\mathrm{Fe} 2+$ is oxidised to $\mathrm{Fe} 3+$ by hephaestin and ceruloplasmin which binds to transferrin. Transferrin will transport iron to the bone marrow to join to form haemoglobin and conduct erythropoiesis. The remainder of iron which is not used in erythropoiesis will be carried by transferrin to be stored in its storage area, i.e. liver, bone marrow, and reticuloendothelial system in the form of ferritin. ${ }^{6}$

Daily iron needs are met by macrophages that conducts iron recycling. This recycling is carried out through the process of phagocytosis of old erythrocytes at the age of 120 days. Lysis and iron erythrocytes are excreted from haemoglobin mediated by heme oxygenase-1. Iron is then stored as ferritin and exported via ferroportin to the bloodstream to its storage area or used for erythropoiesis. ${ }^{7}$

Hepcidin acts as a regulator for iron metabolism. Hepcidin will bind to the ferroportin receptor which causes a reduction in iron absorption in enterocytes. As a result, iron absorption and iron mobilisation to the bone marrow and its storage area (liver, bone marrow, reticuloendothelial system) will decrease. Hepcidin synthesis will increase when iron saturation in transferrin increases and vice versa decrease when iron saturation is low. ${ }^{8}$

When iron saturation increases, the liver will produce hepcidin which will then circulate into the intestine and bind to ferroportin, so that iron transfer from enterocytes to the plasma will be disrupted. Iron will be trapped in enterocytes which eventually enterocytes containing iron will be peeled off and released into the intestinal lumen. If the iron saturation is low, hepcidin formation will decrease, so that ferroportin in the small intestine will be used to transport iron to the blood plasma. The interaction between hepcidin and ferroportin can explain the process of recycling iron in macrophages wherein inflammation hepcidin will increase, and export of iron from macrophages to the small intestine will be disrupted so that iron will be trapped in macrophages. ${ }^{7,9}$

\section{Etiology}

The causes of anemia are varied based on age, gender, and socio-economic status. The leading causes of IDA include reduced iron intake, diminished iron absorption, and loss of iron through bleeding. Excessive menstruation is one of the leading reasons for IDA in premenopausal women. Gastrointestinal bleeding is also one of the most common causes of IDA. Pathology in the digestive tract in patients with IDA varies between $43-86 \%$. The most commonly found pathology is the upper gastrointestinal lesions as much as $39-57 \%$ of total gastrointestinal pathologies found especially peptic ulcer.

Meanwhile, the lower gastrointestinal lesion that is often found is colon carcinoma. ${ }^{4}$ Malabsorption of the digestive tract is one of the main factors for the development of IDA. It can be suspected as a cause especially if the examination does not reveal gastrointestinal bleeding and refractory iron deficiency despite iron supplementation therapy. Celiac disease is one of the conditions that is often found in $5-6 \%$ of patients with IDA. In this disease malabsorption occurs mainly in the duodenum where this is the principal place for iron absorption. Helicobacter pylori infection is often associated with reduced iron absorption. Iron deficiency anemia is also one of the consequences that can occur after a gastric bypass surgery procedure and partial gastrectomy. It happens because duodenal bypass is the leading site of iron absorption and also reduced availability of gastric juice which helps iron absorption. ${ }^{4}$

\section{Diagnosis}

There are several steps to establish the diagnosis of IDA. The first step is taking complete medical history, physical examination, and laboratory tests to determine anemia. The second step is to determine the presence of IDA. The third step is to determine the cause of IDA thorough diagnostic evaluation.

\section{History taking and physical examination}

IDA has different clinical presentations from mild to severe. Complaints that are often experienced by patients include weakness, fatigue, irritability, headache, and dyspnea. ${ }^{4}$ Mental and cognitive functions decrease can also be experienced by patients. IDA is also associated with a prominent neurological sequel. Restless leg syndrome is one of the symptoms of IDA where there is a resistance to move the lower extremity especially at rest. ${ }^{7}$

Other histories that need to be observed is bleeding, gastrointestinal symptoms (abdominal pain, change bowel habit, dysphagia), consumption of painkillers such as aspirin or NSAIDs, 
family history of gastrointestinal malignancies, and haematological abnormalities. The main thing that also needs to be asked is how is the patient's daily diet to identify a decrease in iron intake. ${ }^{10}$ On physical examination pallor or paleness of the conjunctiva and skin associated with anaemia, glossitis, koilonychia, dysphagia will be found. IDA that occurs continuously with severe clinical symptoms will cause Plummer-Vinson Syndrome (post cricoid dysphagia, IDA, oesophagal webs) but this is very rarely found. ${ }^{4}$

\section{Laboratory test}

As to assess the presence of anemia, haemoglobin and hematocrit levels are one of the criteria that need to be examined to be able to establish the diagnosis. In IDA there will be a decrease in haemoglobin and hematocrit. The distribution of haemoglobin varies according to age, gender, pregnancy, height of residence, and history of smoking. According to the World Health Organization (WHO), anaemia is defined as a haemoglobin level below $13 \mathrm{~g} / \mathrm{dl}$ in men over 15 years old, below $12 \mathrm{~g} / \mathrm{dl}$ for non-pregnant women over 15 years old, and under $11 \mathrm{~g} / \mathrm{dl}$ in pregnant women. ${ }^{4,5,11}$ Red blood cells in IDA are described as hypochromic microcytic wherein the complete blood count test found a decrease in mean corpuscular volume (MCV) as well as so did mean corpuscular haemoglobin $(\mathrm{MCH})$. The MCV will reduce as much as $<80 \mathrm{~g} / \mathrm{dl}^{5}$

IDA diagnosis is highly dependent on the interpretation of iron in the blood. According to a study conducted by Peyrin-Biroulet et al. on the management of iron deficiency in various indications, it was found that the most recommended examination was serum ferritin concentration. ${ }^{12}$ Serum ferritin is a good test to assess iron storage indicators and can replace bone marrow examination which is the gold standard for the diagnosis of IDA. Hypothyroidism and ascorbic deficiency can interfere with ferritin synthesis, so these two conditions can also reduce serum ferritin levels other than IDA. The results of the diagnosis with serum ferritin were favourably used with a cut-off of less than $30 \mathrm{ng} / \mathrm{ml}$, which had a sensitivity of $92 \%$ and specificity of $98 \% ., 12$

Serum ferritin is an acute-phase protein, where its level will increase, and its utilization is limited mainly to conditions of inflammation, infection, and malignancy. ${ }^{13}$ Higher cut-offs for the diagnosis of serum ferritin such as $<60 \mathrm{ng} / \mathrm{ml}$ may be necessary for the determination of IDA in patients with liver disorders, alcoholism, and chronic renal failure. ${ }^{4}$

Other laboratory results that can be found in IDA are a decrease in serum iron (SI), decreased transferrin saturation, and an increase in total iron-binding capacity (TIBC). These are due to the reduction in the amount of iron bound to transferrin. Transferrin saturation below $20 \%$ and serum ferritin below $30 \mathrm{ng} / \mathrm{ml}$ are predictors of iron deficiency. ${ }^{13}$

If the diagnosis remains unclear, a serum transferrin receptor (sTfR) examination can be performed. The sTfR will increase in iron deficiency, but the results are not affected by inflammation, infection, age, sex, or pregnancy. This examination can be a useful test to identify iron deficiency in patients with inflammatory diseases. Analysis of sTfR and sTfR-log ferritin index $(<1)$ can help distinguish between IDA and anaemia in chronic disease because sTfR will only increase in IDA condition. ${ }^{5}$ Previous bone marrow biopsy or aspiration examinations were widely used as IDA gold standard for diagnosis. However, because these examinations are invasive and relatively expensive, they are seldom chosen. This bone marrow examination can be selected if the diagnosis of IDA cannot be established only through biochemical examination. ${ }^{4}$

\section{Diagnostic evaluation}

IDA has physiological and pathological causes where additional examinations must be carried out to determine the cause. Gastrointestinal bleeding is the main cause of IDA in men and menopausal women. In a population study conducted in more than 700 adults with IDA, as many as $6 \%$ were diagnosed with malignancies in the gastrointestinal tract. The risk of malignancy increases by $9 \%$ in IDA patients over 65 years. Patients with IDA should be evaluated for occult bleeding, except if through history taking and physical examination it was found that IDA was caused by a mild etiology. ${ }^{13-22}$

In male patients of all ages and menopausal women, it is recommended to perform bidirectional endoscopy (upper colonoscopy and endoscopy). In patients over 50 years old without symptoms from the upper gastrointestinal tract with establishing diagnosis of IDA, the initial diagnostic evaluation that should be carried out is a colonoscopy. ${ }^{15}$ If the colonoscopy results are found negative, then should be continued with the upper endoscopy. ${ }^{4}$

Further diagnostic tests for the small intestine need to be done for patients with IDA without improvement in haemoglobin during the administration of iron therapy, transfusion-dependent, and recurrent anaemia. ${ }^{16}$ The suggested tests include MRI enteroclysis, CT enterography or barium enema. These examinations are not very reliable for the detection of mucosal lesions. However, they can be considered if the patients cannot undergo endoscopy. ${ }^{10}$ In patients with typical endoscopic results and experiencing IDA recurrence, eradication of 
the Helicobacter pylori bacteria needs to be implemented. Helicobacter pylori which colonises can interfere with iron uptake in the gastrointestinal tract and increase iron secretion from the body. ${ }^{10}$

\section{Management}

\section{Oral iron therapy}

Oral iron therapy is the first-line therapy for IDA because it is safe, inexpensive, and useful for restoring the amount of iron in the body. ${ }^{4}$ The recommended dose for adult patients with IDA is ferrous sulphate $200 \mathrm{mg} 2$ times per day. ${ }^{10}$ Other iron compounds such as ferrous fumarate, ferrous gluconate, and iron suspension are also well tolerated. Smaller doses also remain effective with fewer side effects. ${ }^{5}$ The common side effects are nausea, vomiting, and epigastric pain. These were thought to be related to dosage, so it is recommended to give a low dose after meals, and later the dosage can be increased slowly. ${ }^{5}$

Appropriate iron therapy will increase reticulocytes in 3-5 days with peaks on days 8-10. An increase in haemoglobin level of $1 \mathrm{~g} / \mathrm{dl}$ will occur within 2-3 weeks of iron therapy. Returning the average amount of iron will take up to 3-4 months after the haemoglobin starts to return to normal. Oral iron therapy responses must be adequately monitored. If the haemoglobin level does not increase in that period, it should be considered for the administration of intravenous iron therapy and reevaluation of the cause of the condition. Iron tablets must be continued for 3-6 months after the amount of haemoglobin has reached normal levels. ${ }^{4}$

Iron tablets should not be taken together with food because the content of phosphates, phytates, and tannates in food can interfere with iron absorption. Some drugs that work on the stomach such as antacids, proton pump inhibitors, histamine $\mathrm{H}-2$ blockers will reduce iron absorption. Ascorbic acid (250-500 mg) taken together with iron tablets can increase its absorption. ${ }^{13}$

\section{Intravenous iron therapy}

Intravenous iron therapy is indicated in patients with intolerance and does not respond to oral iron therapy, malabsorption, chronic bleeding, haemoglobin level $<6 \mathrm{~g} / \mathrm{dl}$ with poor perfusion, and patients who cannot receive blood transfusion. ${ }^{17,18}$ Through intravenous iron administration, ferritin can increase after administration and reach higher levels compared to oral iron administration. ${ }^{10}$

One of the first intravenous iron therapies used is iron dextran. Iron dextran can be administered in large doses of 200-500 mg in one administration. However, this drug has a high risk of anaphylactic reactions, so it is rarely used. ${ }^{5}$ Other intravenous that is safer to administer includes sodium ferric gluconate (Ferrlecit), iron sucrose, and ferric carboxymaltose. ${ }^{24}$ These drugs are safer to use because the risk of anaphylactic reactions is lower than iron dextran. ${ }^{10}$ Side effects such as hypotension, diarrhoea, nausea, and arthralgia are reduced in frequency with ferric gluconate and iron sucrose than iron dextran. However, side effects can still occur if given in large doses. ${ }^{4}$ Sodium ferric gluconate is usually administered intravenously for eight weeks at a dose of $125 \mathrm{mg}$ of a total dose of 1,000 mg. ${ }^{13,25}$ Sucrose iron is distributed intravenously as much as $200 \mathrm{mg}$ for 5 times in 2 weeks. ${ }^{13}$ If the treatment is given more than recommended, side effects can occur, and patients need repeated administration to restore iron storage to normal. ${ }^{4}$ Other drugs such as iron polymaltose, isomaltose, and ferric carboxymaltose administration in large doses can be administered with minimal risk for side effects. ${ }^{4,26}$

\section{Blood transfusion}

Blood transfusion must be limited, especially in patients with chronic IDA. ${ }^{23}$ The administration of appropriate iron therapy can minimalized the use of blood transfusion. Blood transfusion can be considered in patients with active bleeding with unstable hemodynamics, acute myocardial ischemia, or if all other therapies failed to correct the occurrence of anemia. ${ }^{5,24}$

\section{CONCLUSION}

IDA remains the most commonly encountered health problems in developing countries. This disorder can interfere with cognitive functions and the ability to carry out daily activities. Complete history taking, physical examination, and laboratory test need to be conducted thoroughly to be able to establish the diagnosis of IDA as well as to determine its cause. Male and female patients who have anaemia should be given diagnostic evaluation in the form of endoscopy to find out the reason according to gastrointestinal tract disorders. The management of IDA is focussed on to increase the haemoglobin levels, red blood cells levels, iron storage, and comorbid conditions. Currently used therapies include oral iron therapy which is the first-line therapy, intravenous iron therapy, and blood transfusion.

\section{REFERENCES}

1. Sudoyo AW, Setiyohadi B, Alwi I, Simadibrata M, \& Setiati, S. Buku Ajar Ilmu Penyakit Dalam, Jilid, Edisi V. Jakarta: Interna Publishing; 2009.

2. Alli N, Vaughan J, Patel M. Anemia: Approach to diagnosis. S Afr Med J, 2017;107(1): 23-27. 
3. Kassebaum NJ, Rahmi J, Naghavi M, et al. A systematic analysis of global anemia burden from 1990 to 2010. Blood. 2014;123(5).

4. Liu K, Kaffes AJ. Iron deficiency anemia: a review of diagnosis, investigation and management. Eur J Gastroenterol Hepatol. 2012; 24: 109-116.

5. Jimenez K, Kulnigg-Dabsch S, Gasche C. Management of Iron Deficiency Anemia. Gastroenterology \& Hepatology. 2015; 11(4).

6. Dev S, Babbit JL. Overview of Iron Metabolism in Health and Disease. Hemodial Int. 2017; 21(Suppl 1): S6-S20.

7. Miller JL. Iron Deficiency Anemia: A Common and Curable Disease. Cold Spring Harb Perspect Med. 2013.

8. Keshav S, Stevens R. New concepts in iron deficiency anemia. British Journal of General Practice. 2017.

9. Pollin V, Coriat R, Perkins G, et al. Iron deficiency: from diagnosis to treatment. Digestive and Liver Disease. 2013; 45: 803-809.

10. Goddard AF, James MW, Mclntyre AS, Scott BB. Guidelines for the management of iron deficiency anemia. Gut. 2011; 60: 1309-1316.

11. World Health Organization. Iron Deficiency Anemia: Assesment, Prevention, and Control A Guide for Programme Managers. Geneva, World Health Organization: 2001.

12. Peyrin-Biroulet L, Williet N, Cacoub P. Guidelines on the diagnosis and treatment of iron deficiency across indications: a systematic review. Am J Clin Nutr. 2015; 102: 1585-1594.

13. Killip S, Bennett JM, Chambers M. Iron Deficiency Anemia. Am Fam Physician. 2007; 75: 671-678.

14. Sivanganam, S., Weta, W. Gambaran tingkat kepatuhan ibu hamil mengkonsumsi tablet besi di wilayah kerja puskesmas Sidemen tahun 2015. Intisari Sains Medis 2017; 8(2): 135-138. DOI: 10.1556/ism.v8i2.128

15. Zahra, A.L., Putrawan, I.B., Dharmayuda, T.G. Karakteristik anemia pada lansia di RSUP Sanglah Denpasar pada bulan Januari-Juni 2017. Intisari Sains Medis 2019; 10(2): 155-158. DOI: 10.15562/ism.v10i2.241
16. Wijayanti, E., Retnoningrum, D., Hendrianintyas, M. Hubungan petanda inflamasi dan hemoglobin pada obesitas di Fakultas Kedokteran Universitas Diponegoro periode Mei-September 2018. Intisari Sains Medis 2019; 10(1):242-246. DOI: 10.1556/ism.v10i1.347

17. Sari, A., Pamungkasari, E.P., Dewi, Y.L.R. The addition of dates palm (Phoenix dactylifera) on iron supplementation $(\mathrm{Fe})$ increases the hemoglobin level of adolescent girls with anemia. Bali Medical Journal 2018; 7(2): 356-360. DOI: 10.15562/bmj.v7i2.987

18. Tala, Z.Z., Darlan, D.M., Tantono, J., Arrasyid, N.K Accuracy in measuring hemoglobin concentration using portable hemoglobinometer method. Bali Medical Journal. 2017; 6(1): 121-124. DOI: 10.15562/bmj.v6i1.395

19. WHO. Worldwide prevalence of anaemia 1993-2005. Geneva: WHO; 2008.

20. Bianchi VE. Anemia in the Elderly Population. J Hematol. 2014;3(4):95-106.

21. Le CHH. The Prevalence of Anemia and Moderate-Severe Anemia in the US Population (NHANES 2003-2012). PloSONE 2016; 11(11).

22. Geisel T, Martin J, Schulze B, Schaefer R, Bash M, Virgin G, Stein J. An Etiologic Profile of Anemia in 405 Geriatric Patients. Hindawi Publishing Corporation. 2014;10.1155.

23. Suherlim D, Lubis L, Permana H. Korelasi kadar hemoglobin dengan saturasi oksigen pada guru besar Universitas Padjadjaran. Bali Anatomy Journal. 2018; 1 (2): 26-29.

24. Camaschella C. Iron-Deficiency Anemia. $N$ Engl J Med. 2015; 372:1832-1843. DOI: 10.1056/NEJMra1401038

25. Killip S, Bennett JM, Chambers MD. Iron-Deficiency Anemia. Am Fam Physician. 2007; 75 (5): 671-678.

26. Clark SF. Iron Deficiency Anemia. Nutr Clin Pract. 2008; 23: 128-141. doi: 10.1177/0884533608314536

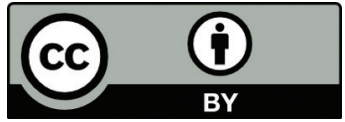

This work is licensed under a Creative Commons Attribution 